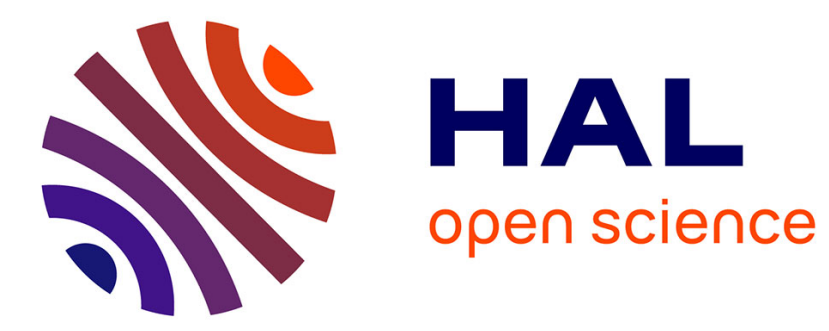

\title{
Influence de l'état boisé sur la pluviosité
} J.-J.-Ed. Martin

\section{- To cite this version:}

J.-J.-Ed. Martin. Influence de l'état boisé sur la pluviosité. Revue forestière française, 1950, 4, pp.196-197. 10.4267/2042/27670 . hal-03382085

\section{HAL Id: hal-03382085 \\ https://hal.science/hal-03382085}

Submitted on 18 Oct 2021

HAL is a multi-disciplinary open access archive for the deposit and dissemination of scientific research documents, whether they are published or not. The documents may come from teaching and research institutions in France or abroad, or from public or private research centers.
L'archive ouverte pluridisciplinaire HAL, est destinée au dépôt et à la diffusion de documents scientifiques de niveau recherche, publiés ou non, émanant des établissements d'enseignement et de recherche français ou étrangers, des laboratoires publics ou privés. 
Cette transformation, avec ses incidences législatives, n'irait pas sans soulever de nombreuses difficultés. Et pourtant n'est-elle pas inéluctable parce qu'elle est dans le sens de l'évolution économique générale ?

Elle présenterait d'ailleurs des avantages pour le rendement non plus seulement des exploitations, mais des forêts elles-mêmes. Les économies réalisées sur les frais d'entretien des routes, et la plusvalue donnée aux bois permettraient de consacrer des crédits plus substantiels aux travaux de reboisement. Il ne serait plus nécessaire d'attendre 40 ou 50 ans une régénération naturelle parfois problématique. Il ne resterait alors qu’à posséder en nombre suffisant des techniciens confirmés, pour réaliser une sylviculture plus intensive.

A. BÉrard.

\section{INFLUENCE DE L'ÉTAT BOISE SUR LA PLUVIOSITE}

Indice bibliographique: Ir.14: $91.3(44.71$ - 44.77)

Dans les recherches, d'un intérêt certain, concernant l'influence de l'état boisé sur le régime des pluies, il ne me parait pas douteux que, si elle peut être faite, la comparaison des précipitations actuelles dans la région landaise (essentiellement; sud de la Gironde et Landes) et celles relevées avant le boisement massif qui en a été effectué au siècle dernier, serait un document de grande valeur.

Or, le Service de la Climatologie de 1'O. N. M. a achevé en I946, sous le contrôle de son Directeur, M. SAnson, une carte pluviométrique de la France, basée sur la moyenne de 40 années, de I89I à I930, document de tout premier ordre et qui doit être bien voisin de la perfection. Pour ce qui nous occupe, nous avons là les chiffres les plus exacts qu'on puisse souhaiter pour la période où le boisement complet donnait toute leur puissance aux effets de la forêt. Il restait à trouver le plan de comparaison pour une périocle antérieure à 1850 - et là, hélas, les affaịres vont moins bien.

Après échange de correspondance avec M. le Directeur de l'Etablissement Central Météorologique, j'ai été autorisé à consulter sur place la documentation. Elle est abondante depuis I860, mais, malheureusement, très pauvre pour les périodes antérieures.

Un excellent document pour St Sever (20 km. au Sud de Montde-Marsan) m'a paru acceptable. Il portait sur une période com- 
prise entre $\mathrm{I} 782$ et $\mathrm{I} 8 \mathrm{I} 8$ avec une interruption de I797 à I80o. D'autre part, j'ai pu relever pour Toulouse des observations de I782 à I890 et de I806 à I8I8; éliminant pour St-Sever les I5 années qui manquaient à Toulouse, il restait 22 années communes aux deux stations qui ont permis la comparaison suivante :

\begin{tabular}{|c|c|c|c|}
\hline & OBSERVATIONS & IOMÉTRIQUES & \\
\hline Stations & 22 années entre & Actuelles & ECART \\
\hline - & - & - & - \\
\hline St-Sever .... & $709 \mathrm{~m} / \mathrm{m}$ & $9.38 \mathrm{~m} / \mathrm{m}$ & $+32 \%$ \\
\hline Toulouse .... & $684 \mathrm{~m} / \mathrm{m}$ & $684 \mathrm{~m} / \mathrm{m}$ & $0 \%$ \\
\hline Paris & $564 \mathrm{~m} / \mathrm{m}$ & $598 \mathrm{~m} / \mathrm{m}$ & $+6 \%$ \\
\hline
\end{tabular}

Comparaison impressionnante. Sans tabler absolument sur cet écart de près de $\mathrm{I} / 3$ établi sur une base un peu maigre, je pense que cela situe à au moins $25 \%$ l'augmentation des pluies sur la région landaise du fait de leur boisement.

Chambéry - Février I950.

J.-J.-Ed. Martin.

\section{La disparition du chêne dans les taillis sous futaie et la concurrence vitale}

Quand on parle de la disparition du chêne dans les taillis sous futaie, on ne fait pas toujours entre les différents sols les distinctions qui s'imposent.

En sol siliceux pauvre, les cépées sont rares. La concurrence du fait des rejets est peu redoutable. Les coupes sont souvent peuplées de bouleaux, mais le couvert n'est pas três gênant et les semis de chêne ne se trouvent pas en mauvaise posture; ils se maintiennent aisément jusqu'au moment où l'exploitation du taillis, accompagnée de la coupe de certaines réserves, viendra les sauvè définitivement.

En sol argileux au contraire, les rejets sont vigoureux; en sol calcaire, les essences sont nombreuses, les morts-bois abondants. Dans ces deux cas, au bout de peu d'années, les semis de chêne sont étouffés radicalement. Ils ne peuvent persister que dans des stations particulières: le long des chemins, les places à charbon, par-ci, par-là, sous les trembles dans les " combes ». 